\title{
Building Energy Prediction for Early-Design-Stage Decision Support: A Review of Data-driven Techniques
}

\author{
Aman Batish $^{1, *}$, Avlokita Agrawal $^{1}$ \\ ${ }^{1}$ Department of Architecture \& Planning, Indian Institute of Technology, Roorkee, India \\ *corresponding author, e-mail: abatish@ar.iitr.ac.in
}

\begin{abstract}
Building Performance Simulation (used to assess and validate claims about energy requirement of buildings), is often carried out during later design stages, when it is practically difficult to incorporate design changes. In reality, many design decisions affecting Energy requirement of buildings are taken at an early stage, when adequate information to support such decisions is not available or viable due to lack of tools. This paper presents the suitability of data driven techniques, particularly Artificial Intelligence and Machine learning, for early-design-decision support tools through a systematic review of literature. It highlights their potential due to robust prediction capabilities and forms groundwork for further research to develop an earlydesign-decision support tool.
\end{abstract}

\section{Introduction}

\section{Background: Building energy consumption trends}

Buildings consume a large share of the total end use of energy. In Residential and Commercial sectors, a major part of the energy consumption takes place in buildings (Laustsen 2008). As per IEA statistics for energy consumption for 2004-05, these two sectors accounted for almost $40 \%$ of the final energy use in the World. Residential and Commercial \& Public Services sectors consumed $49 \%$ of the world electricity in the year 2015 (International Energy Agency, 2017), indicating an upward trend.

\section{Need for predicting building energy consumption}

Not only do buildings consume a large chunk of end use energy but also, 'the energy efficiency of new buildings determines the building sector's energy consumption for far longer than other end-use sectors components determine their sector's efficiency'(Laustsen, 2008).
Therefore, in order to manage the demand for energy in buildings and also to make buidlings more energy efficient, it is necessary to predict and optimize building energy consumption. This has led the use of Buidling Performance Simulation (BPS) and other techniques for assessing Building Energy Performance (BEP).

\section{Need for early design decision support tools}

It has been widely observed that, 'design decisions made in the early stages have major impact on the final building costs and performance' (Löhnert et al, 2003 cited in Østergård, Jensen, and Maagaard, 2017). Therefore, there is a need for tools and techniques to help architects, along with other professionals and stakeholders in the building industry (developers/ owners), take these decisions wisely by making informed choices in Early Design Stage (EDS).

Existing Building Codes and Green Rating Systems, such as Energy Conservation Building Code (Bureau of Energy Efficiency, 2017) and IGBC Green Homes rating (Indian Green Building Council, 2012) in India, address various building components and their impact on the energy performance through various methods, such as Prescriptive, Trade-off and BPS approaches. However, these methods have limitations in terms of adaptability and use by Architects, especially in EDS.

Studies undertaken on the existing BPS tools show that, 'a large number of architects surveyed (74\%) do not use BPS in their day-to-day practice'(Soebarto et al., 2015) and these tools are perceived to be 'inadequate, user hostile and too incomplete' by architects (Attia et al., 2012), particularly during EDS. Architects usually outsource BPS at a substantial cost. It is often performed in late design stages (usually after Building Approval), when there is not much scope left for incorporating corrective changes in design (Figure 1).

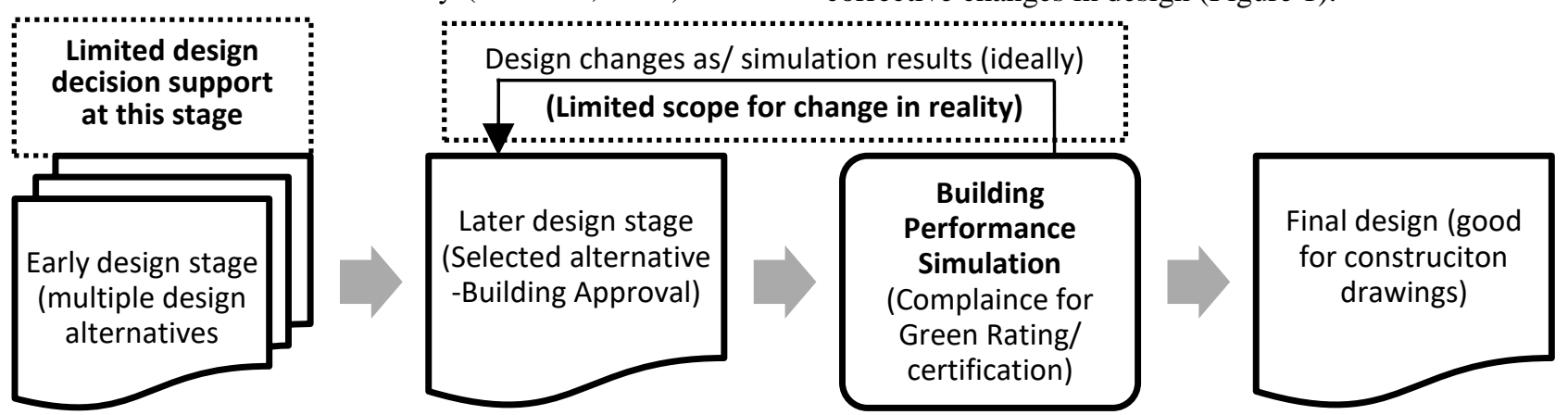

Figure 1: Typical process flow-chart of design development for 'Green Building' Certification/Rating 
Further, BPS is a specialized task involving 3D modelling and requires detailed physical information like building geometry, which may not be available in EDS. Bambardekar and Poerschke (2009) and Bazjanac et al. (2011) have aptly summed up the limitations of using BPS in EDS. Consequently, there is limited design decision support available to quickly assess and evaluate the Energy Performance of multiple design options in EDS.

Hence, there is a need to explore other techniques that can be adapted for Building Energy Prediction \& Optimization for this purpose.

It is important to note that, BPS is an appropriate tool to assess BEP in later stages when detailed design information is available such as for checking compliance of building designs with codes and rating systems. However, this study focuses specifically on the suitability of various BEP evaluation and prediction techniques for EDS when detailed design information may not be available at all. The statements regarding suitability of different techniques should be strictly viewed in this light only, and not as generic evaluations of performance.

\section{Aim, Methodology \& Objectives}

This study aims to examine the suitability of existing Building Energy Prediction and Optimization techniques for developing Building Energy Models suitable for early-design-decision support tools.

A systematic review of scientific literature, like contemporary and recent articles (past 10 to 15 years) published in top tier journals, authoritative books on specific techniques/subject matter, energy conservation codes etc. was carried out for this purpose.

The objectives included:

- Classification of existing techniques on the basis of their methodology.

- Understanding their methodology and working and the modeling approach used.

- Analyzing the specific areas of use of these techniques (in context of building energy).

- Assessing and comparing the performance of various techniques.

\section{Classification of Building Energy Prediction and Optimization Techniques}

Zhao and Magoulès (2012) have classified buildingenergy prediction methods into five types, namely:

1. Engineering methods: These use physical principles to calculate thermal dynamics and energy behaviour. They can be sub-divided into:

- Detailed comprehensive methods -based on elaborate physical functions or thermal dynamics to calculate the energy consumption precisely, step-bystep. Software tools like DOE-2, Energyplus, BLAST, ESP-r have been developed to evaluate energy efficiency in buildings.
- Simplified methods -steady state methods like 'Degree Day' method and 'Bin' also known as temperature frequency method.

2. Statistical methods: These use statistical techniques to correlate the energy consumption or energy index with influencing variables. Also referred to as empirical models developed from historical data. Common techniques inlclude Linear regression, Principal Component Analysis (PCA), AutoRegression with eXtra inputs (ARX), AutoRegressive Integrated Moving Average (ARIMA), ARIMA with eXternal inputs (ARIMAX) and a regression based method called Conditional Demand Analysis (CDA).

3. Neural Networks: These are Artificial Intelligence based models. Artificial Neural Networks (ANNs) have been cited as the most widely used AI models for building energy prediction. Sub-types include: Back Propagation Neural Networks (BPNN), Feed forward Neural Networks (FNN), Recurrent Neural Networks, Fuzzy Neural Networks etc. and ensemble techniques -using ANNs in combination with Genetic Algorithm (GA) and data mining techniques like Classification And Regression Trees (CART), Chi-Squared Automatic Interaction Detector (CHAID), exhaustive CHAID, Boosting Trees, Random Forest, Support Vector Machine (SVM), k-Nearest Neighbor (k-NN).

4. Support Vector Machines (SVM): These are highly effective models in solving non-linear problems even with small quantities of training data.

5. Grey Models: These are models where the information of a system is known partially.

ANN and SVM can be clubbed together into Artificial Intelligence \& Machine learning based techniques.

Foucquier et al. (2013) use the following classification:

1. Physical Models or Building Thermal Behavior Models: These are based on solving of equations describing physical behavior of heat transfer. Sub divided into: Computational Fluid Dynamics (CFD), Zonal approach and Multi-zonal or nodal approach

2. Statistical methods using machine learning: These include statistical techniques and AI based techniques like ANN and SVM already mentioned above.

3. Hybrid models: These are based on combining statistical and physical models.

Physical models essentially use Engineering methods, as mentioned in Zhao and Magoulès (2012)

Fumo (2014) presented classifications used from five studies reviewed in his paper. Important ones are:

1. ASHRAE Handbook 2009 classification:

a) Forward (classical) approach: Equations describing physical behaviour of systems and their inputs are used to predict output (descriptive/ physical/ engineering/ white box approach) 
b) Data-driven (inverse) approach: Input and output variables governing the performance of the systems are measured and this known data is used to define a mathematical description of the system. These are further categorized into 3 types:

- Empirical or "Black Box" approach: A simple or multivariate regression is performed to find the relationship between outputs and input parameters. Calibrated simulation approach: Uses a simulation computer program that has been calibrated with actual measured data to give better predictions.

- Grey-Box approach: Firstly, a mathematical model is developed to describe the building's physical features that impact its energy consumption. Secondly, statistical methods are used to identify parameters and determine their values.

2. Another broad classification mentioned by Swan and Ugursal (2009) cited in this paper:

- Top-down approach: Uses macro-economic indicators like GDP and price indices etc. to predict their effect on energy consumption in residential sector without distinguishing energy consumption due to individual end uses. (this approach is out of the scope of this study)

- Bottom up approach: Involves predicting energy consumption of sector using input parameters in the lower hierarchical level and may account for individual end uses. Further classified into statistical and engineering approaches (described in detail already)

Forward or Classical approach is the same as Physical/Engineering method. Calibrated simulation is "the process of using an existing building simulation program and 'tuning' or calibrating the various inputs to the program so that observed energy use matches closely with that predicted by the simulation program"(Agami Reddy 2006). Calibrated engineering models developed with whole building simulation tools have gained particular interest because they allow for reliable simulations.

H. Wang and Zhai (2016) have further categorized detailed building energy simulation into the following types:

1. Conduction Transfer Function method (CTF): This is one of the conventional approaches used for transient heat transfer calculations. Used in simulation software like BLAST, TRNSYS and Energyplus.
2. Thermal Response Factor method: another common approach for transient heat transfer calculation. Not suitable for radiant heat transfer. Adopted in DOE-2.

3. Radiant Time Series (RTS) method: used for cooling load calculations, especially radiant cooling load.

4. Lumped Parameter models: building structure elements have characteristics of thermal resistance and capacitance and hence their thermal performance can be as simulated as a reduced order lumped parameter (resistance-capacitance) model.

Østergård, Jensen, and Maagaard (2016) mention an important approach called Meta-Model, defined as a simplified model of a model. This can be categorized in hybrid or grey box techniques. It involves constructing a model from a large set of validated, detailed simulations using BPS software and analysis of input -output relationships observed in the data to establish a mathematical relationship (Hygh et al., 2012). The data used for constructing a meta-model may be experimental (obtained from simulations) or observed (real time data from sensors/ meters/ weather data). This technique forms an important area of interest for this study. The process flow chart for the meta-model approach is illustrated in Figure 2.

\section{Summary of Classifications used in Literature}

Building Energy Prediction techniques can be classified into two broad categories, namely:

- Top-down approaches: not an area of interest and excluded from this study

- Bottom-up approaches: these can be further categorized into:

1. Descriptive / Engineering / Theoretical / Physical / Classical or 'White Box' models, using detailed or simplified methods (not an area of interest)

2. Data driven / Empirical or 'Black Box' models, using any of the various statistical or AI and machine learning techniques. An ensemble of these techniques can also be used to improve the performance or accuracy of these techniques.

3. Hybrid or 'Grey Box' models, using a combination of Physical and data-driven approaches. For example meta-modeling using statistical or AI based techniques with simulated data obtained from Building Performance Simulation software like Design Builder or Ecotect.

An organized summary is presented in Table 1 overleaf.

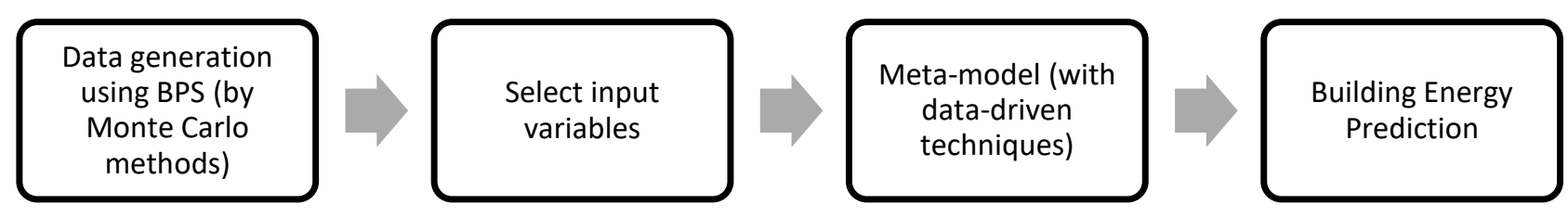

Figure 2: Process flow-chart of Meta-modelling approach 
Table 1: Classification of Building Energy Prediction Techniques/Approaches

\begin{tabular}{|c|c|c|c|c|c|}
\hline \multicolumn{6}{|c|}{ BUILDING ENERGY PREDICTION APPROACHES } \\
\hline \multirow{3}{*}{$\begin{array}{c}\text { Top- } \\
\text { Down } \\
\text { Approach } \\
\text { (not } \\
\text { within the } \\
\text { scope of } \\
\text { this study) }\end{array}$} & \multicolumn{2}{|c|}{$\begin{array}{c}\text { Descriptive/Engineering/Theoretical/ } \\
\text { Physical OR CLASSICAL Methods } \\
\text { (White Box) }\end{array}$} & \multicolumn{2}{|c|}{$\begin{array}{c}\text { Data Driven/Empirical Methods } \\
\text { (Black Box) }\end{array}$} & $\begin{array}{l}\text { Hybrid Methods } \\
\text { (Grey Box) }\end{array}$ \\
\hline & $\begin{array}{l}\text { Detailed Methods } \\
\text { [Software] }\end{array}$ & $\begin{array}{l}\text { Simplified } \\
\text { Methods }\end{array}$ & Statistical Methods & $\begin{array}{l}\text { AI / Machine } \\
\text { learning } \\
\text { Methods }\end{array}$ & \multirow{2}{*}{$\begin{array}{l}\text { Combination of } \\
\text { physical and data } \\
\text { driven methods } \\
\text { using machine } \\
\text { learning as physical } \\
\text { parameter estimator } \\
\text {-Meta modelling } \\
\text { (Using Monte Carlo } \\
\text { simulations) }\end{array}$} \\
\hline & $\begin{array}{l}\text { - Computational } \\
\text { Fluid Dynamics } \\
\text { (CFD) (3D) } \\
\text { approach } \\
\text { [FLUENT, } \\
\text { COMSOL Multi- } \\
\text { physics, MIT-CFD, } \\
\text { PHOENICS-CFD } \\
\text { etc.] } \\
\text { - Zonal (2D) } \\
\text { [SPARK] } \\
\text { - Multizone or Nodal } \\
\text { (1D) apporach } \\
\text { [TRNSYS, } \\
\text { EnergyPlus, ESP-r, } \\
\text { eQUEST, IDA-ICE } \\
\text { etc.] } \\
\text { - Conduction } \\
\text { Transfer Function } \\
\text { (CTF) method } \\
\text { [BLAST, TRNSYS } \\
\text { \& Energyplus] } \\
\text { Thermal response } \\
\text { factor method } \\
\text { [DOE-2] } \\
\text { Radiant time series } \\
\text { method (RTF) } \\
\text { Lumped Parameter } \\
\text { models }\end{array}$ & $\begin{array}{l}\text { - Degree Day } \\
\text { method } \\
\text { - Temperature } \\
\text { Frequency } \\
\text { method (bin) }\end{array}$ & $\begin{array}{l}\text { - Linear Regression } \\
\text { - Principal } \\
\text { Component } \\
\text { Analysis (PCA) } \\
\text { - Auto-Regressive } \\
\text { Moving Average } \\
\text { (ARMA) } \\
\text { - Auto-Regressive } \\
\text { Integrated Moving } \\
\text { Average (ARIMA) } \\
\text { - Multiple Linear } \\
\text { Regression (MLR)/ } \\
\text { Conditional } \\
\text { Demand Analysis } \\
\text { (CDA) } \\
\text { Other tools like: } \\
\text { Ordinary least } \\
\text { square regression } \\
\text { (OLSR), } \\
\text { Polynomial } \\
\text { regression, } \\
\text { Exponential } \\
\text { regression, } \\
\text { Multivariate } \\
\text { adaptive regression } \\
\text { spline (MARS), } \\
\text { Case based } \\
\text { reasoning (CBR) } \\
\text { etc. } \\
\text { Ond }\end{array}$ & $\begin{array}{l}\text { - Artificial } \\
\text { Neural Network } \\
\text { (ANN) } \\
\text { - Support Vector } \\
\text { Machine } \\
\text { (SVM) } \\
\text { - Genetic } \\
\text { Algorithm } \\
\text { (GA) } \\
\text { - Particle Swarm } \\
\text { Optimization } \\
\text { (PSO) } \\
\text { - Ensemble } \\
\text { models using a } \\
\text { combination of } \\
\text { AI techniques }\end{array}$ & \\
\hline
\end{tabular}

Table 2: Comparative between the three basic types of Energy Modelling techniques

\begin{tabular}{|c|c|c|c|c|}
\hline $\begin{array}{l}\text { TECHNIQUE/ } \\
\text { ASPECT }\end{array}$ & $\begin{array}{l}\text { DESCRIPTIVE/ } \\
\text { ENGINEERING/ } \\
\text { THEORETICAL/ } \\
\text { PHYSICAL METHODS } \\
\text { (WHITE BOX) }\end{array}$ & $\begin{array}{l}\text { DATA } \\
\text { DRIVEN/EMPIRICAL } \\
\text { METHODS (BLACK } \\
\text { BOX) }\end{array}$ & $\begin{array}{l}\text { HYBRID METHODS } \\
\text { (GREY BOX) }\end{array}$ & REFERENCE \\
\hline $\begin{array}{l}\text { Prediction } \\
\text { methodology } \\
\text { and approach }\end{array}$ & $\begin{array}{l}\text { Use thermo-dynamic equations } \\
\text { to calculate energy behaviour } \\
\text { (Detailed methods) } \\
\text { OR } \\
\text { steady state equations } \\
\text { (simplified methods) }\end{array}$ & $\begin{array}{l}\text { Correlate Energy related } \\
\text { output/ dependent } \\
\text { variables with input/ } \\
\text { independent variables to } \\
\text { express Energy as a } \\
\text { function of these variables }\end{array}$ & $\begin{array}{l}\text { Use Engineering/ } \\
\text { physical methods in } \\
\text { combination with Data } \\
\text { driven methods }\end{array}$ & $\begin{array}{l}\text { (Zhao and } \\
\text { Magoulès, 2012) } \\
\text { (Foucquier et al., } \\
\text { 2013) } \\
\text { (Hester, Gregory, } \\
\text { and Kirchain, } \\
\text { 2017) }\end{array}$ \\
\hline $\begin{array}{l}\text { Information } \\
\text { about Building } \\
\text { geometry }\end{array}$ & $\begin{array}{l}\text { A detailed description is } \\
\text { required }\end{array}$ & $\begin{array}{l}\text { Detailed description is not } \\
\text { required }\end{array}$ & $\begin{array}{l}\text { A rough description is } \\
\text { enough }\end{array}$ & $\begin{array}{l}\text { (Foucquier et al., } \\
\text { 2013) }\end{array}$ \\
\hline $\begin{array}{l}\text { Training data } \\
\text { (Data can be } \\
\text { real or } \\
\text { simulated) }\end{array}$ & No training data required & $\begin{array}{l}\text { A large amount of } \\
\text { training data collected } \\
\text { over an exhaustive period } \\
\text { of time is required }\end{array}$ & $\begin{array}{l}\text { A small amount of } \\
\text { training data collected } \\
\text { over a short period of } \\
\text { time is required }\end{array}$ & \\
\hline $\begin{array}{l}\text { Physical } \\
\text { interpretation } \\
\text { of results }\end{array}$ & $\begin{array}{l}\text { Results can be interpreted in } \\
\text { physical terms }\end{array}$ & $\begin{array}{l}\text { Difficult to interpret } \\
\text { results in physical terms }\end{array}$ & $\begin{array}{l}\text { Results can be } \\
\text { interpreted in physical } \\
\text { terms }\end{array}$ & \\
\hline
\end{tabular}




\section{The Working of various techniques}

A broad comparative between the three basic types of BEP techniques, based on methodology and approach adopted for modelling, building information \& data required and the interpretability of results, is presented in Table 2.

Data-driven techniques and Hybrid methods constitute the area of interest for this study, particularly models using data obtained from BPS software like Design Builder or Ecotect in combination with statistical or AI / machine learning algorithms. A brief overview of two data driven techniques -Multiple Linear Regression (Statistical technique) and Artificial Neural Network (AI based technique) is presented hereafter.

\section{Multiple Linear Regression (MLR)}

Linear regression based models express Building Energy (dependent or response varibale) as a linear function of one or several input variables (independent variables or predictor variables) generating an equation of the general form:

$$
y\left(x_{1} \ldots x_{n}\right)=\alpha_{0}+\alpha_{1} x_{1}+\alpha_{2} x_{2}+\alpha_{3} x_{3}+\ldots .+\alpha_{n} x_{n}+\varepsilon
$$

where,

$\mathrm{x}_{\mathrm{i}}$ is an input parameter (predictor/ independent variable) influencing the value of $y$ (dependent variable).

$\alpha_{0}$ is the intercept of the regression line (value of $y$ when all other parameter values are zero).

$\alpha_{\mathrm{i}}$ the regression coefficients (or weights associated with each variable).

$\varepsilon$ is an error associated with the regression which is assumed to be randomly distributed.

The goodness-of-fit of the model is indicated by Coefficient of Determination $\mathrm{R}^{2}$, a mesaure of variance in y explanined by the parameters included in model.

Artificial Neural Networks (ANNs) (Haykin, 2008)

ANNs are based on the structure of the human brain and are mathematical representations of its working. They derive from their computational strength from two facts -their massively parallel distributed structure and their ability to learn and therefore, generalize. ANNs can, therefore, produce resonable outputs for inputs not encountered during training. These infromation processing capabilities make it possible for the ANNs to find good approximate solutions to complex (large scale) problems that are intractable.

Some useful properties and capabilities of ANNs are:

1. Non-linearity: ANN is a non-linear statistical technique.

2. Input-output mapping: the network learns from the examples by constructing an input-output mapping for the problem at hand through a 'training' process.

3. Adaptivity: ANNs have a built in capability to adapt and can be easily retrained to deal with minor changes in the operating environmental conditions.

4. Fault tolerance: ANNs exhibit a graceful degradation in performance rather than catastrophic failure.
The modelling process for a neuron labelled $\boldsymbol{j}$ (Figure 3 ) can be explained as below:

- Neuron j receives an input signal from a synapse connected to neuron $\mathrm{i}$ multiplied by a synaptic weight wji (with a positive or negative value)

- The weighted inputs are summed up by a linear combiner (summation junction).

- An activation function is used to limit the amplitude of output of the neuron.

- A bias bj is applied to increase or lower the net input of the activation function.

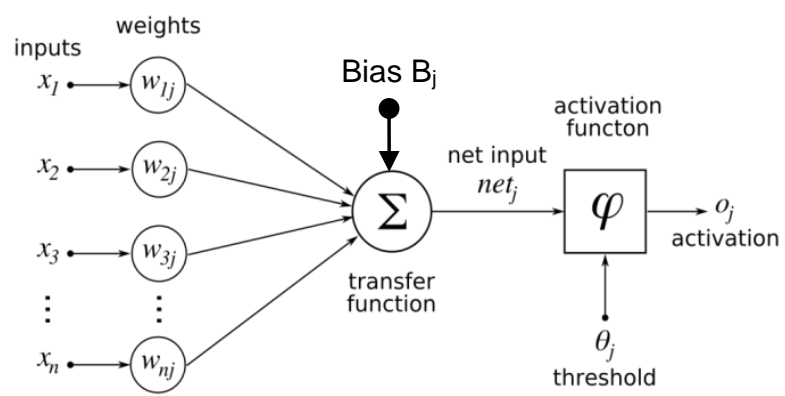

Figure 3: Mathematical model of a Non-linear neuron cell labelled ' $j$ ' adapted from (Haykin, 2008)

The process can be mathematically described in two equations; a Linear combiner function

$$
\mathrm{u}_{\mathrm{j}}=\sum_{i=1}^{m} \quad \mathrm{w}_{\mathrm{ji}} \mathrm{x}_{\mathrm{i}}
$$

and an Activation function

$$
\mathrm{y}_{\mathrm{j}}=\varphi\left(\mathrm{u}_{\mathrm{j}}+\mathrm{b}_{\mathrm{j}}\right)
$$

Where,

$\mathrm{u}_{\mathrm{j}}$ is the linear combiner output.

$\mathrm{x}_{1}, \mathrm{x}_{2}, \mathrm{x}_{3} \ldots \mathrm{x}_{\mathrm{n}}$ are input signals.

$\mathrm{w}_{\mathrm{j} 1}, \mathrm{w}_{\mathrm{j} 2}, \mathrm{w}_{\mathrm{j} 3}, . . \mathrm{W}_{\mathrm{jn}}$ are respective synaptic weights (initial weights are randomly chosen).

$\varphi($.$) is the activation function and b_{j}$ is the bias.

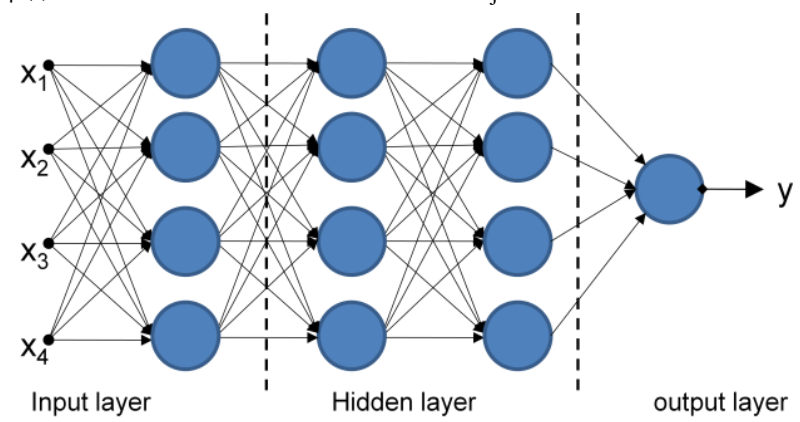

Figure 4: Mathematical representation of a Neural Network with 2 hidden layers having 4 neurons each

The activation function $\varphi$ (.) is usually defined as a Sigmoid function of the form

$$
f(x)=\frac{1}{1+e^{-x}}
$$

It could, however, also be a linear, step or logistic function as/ nature of problem.

A series of such Neurons can be grouped together to form a Neural Network as in the human brain (Figure 4).

\section{Parameter selection for Data-driven Models}

Parameter selection is vital for model accuracy. It should be grounded on a sound theoratical understanding of the 
heat exchange process in a building. A Heat Balance Equation (Eqn. 5) explains the process mathematically:

$$
\mathrm{Q}_{\mathrm{i}}+\mathrm{Q}_{\mathrm{s}} \pm \mathrm{Q}_{\mathrm{c}} \pm \mathrm{Q}_{\mathrm{v}} \pm \mathrm{Q}_{\mathrm{m}}-\mathrm{Q}_{\mathrm{e}}=0
$$

where,

$\mathrm{Q}_{\mathrm{i}}$ is the internal heat gain from occupants or lighting equipment etc.

$\mathrm{Q}_{\mathrm{s}}$ is the heat gain from solar radiation

$\mathrm{Q}_{\mathrm{c}}$ is the heat gain/loss by conduction

$\mathrm{Q}_{\mathrm{v}}$ is the heat gain/loss by convection

$\mathrm{Q}_{\mathrm{m}}$ is the heat gain/loss by mechanical means like HVAC equipment

$\mathrm{Q}_{\mathrm{e}}$ is the heat loss by evaporative cooling on building surfaces. (Koenigsberger et al. 2010)

The energy performance of buildings is dependent on several factors/ parameters, incorporated directly or indirectly in Equation 5. For example, the Conduction Heat Flow Rate $\left(Q_{c}\right)$ through a wall with area ' $A$ ' and Thermal Transmittance (U-value), when a temperature difference $\Delta \mathrm{T}=\mathrm{T}_{\mathrm{in}}-\mathrm{T}_{\text {out }}$ exists between the inside and outside surfaces, is calculated as:

$$
\mathrm{Q}_{\mathrm{c}}=\mathrm{A} \times \mathrm{U} \times \Delta \mathrm{T}
$$

Clearly, the heat gained/ lost is dependent on the parameters Wall Area (A) and Thermal Transmittance (U). However, in case of solar heat gain from windows, the Radiation Heat Flow Density may vary with the orientation of the window and additionally, with any shading devices used. Further, windows will contribute to both conduction and radiation heat flow rate, which may lead to a co-linearity between the predictor variables. Moreover, the impact of predictor variables on energy consumption may not be simply 'additive' or linear but 'multiplicative' and therefore non-linear. Hence, a Regression Model (such as expressed by equation 7) cannot accurately estimate the impact of the predictor variables 'area of wall' and 'U-value of wall' on heat gain/loss inside a building (and consequently, the 'Cooling Load' (CL)).

$$
\mathrm{CL}=\beta_{0}+\beta_{1} * \mathrm{~A}_{\mathrm{wall}}+\beta_{2} * \mathrm{U}_{\text {wall }}
$$

The strategy suggested to overcome this problem is, to add a product term to the main effect model (Jaccard and Turrisi, 2003; Cortina, 1993). This strategy was also used by Hygh et al. (2012) to refine their model. Doing this transforms equation 7 as below:

$$
C L=\beta_{0}+\beta_{1} * A_{\text {wall }}+\beta_{2} * U_{\text {wall }}+\beta_{3} * A_{\text {wall }} * U_{\text {wall }}
$$

which is a more realistic model of the process.

\section{Trends for use of Modelling techniques}

Amasyali and El-Gohary (2018) reviewed 53 papers using various data driven techniques to make building energy predictions. Their analysis showed that, $47 \%$ of the studies reviewed employed the use of ANNs, which is significantly more than statistical techniques (24\%), pointing towards a greater interest shown by researchers in this area. In fact, $72 \%$ of the studies used AI/ Machine learning techniques (ANN $+\mathrm{SVM})$. A greater interest in AI techniques is attributable to better performance.

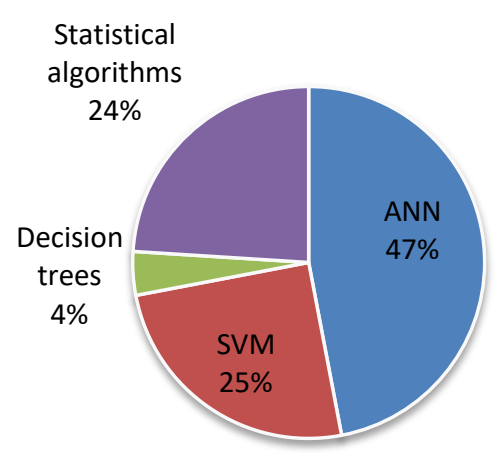

Figure 5: Frequency of use of data driven techniques in various studies (Amasyali and El-Gohary 2018)

A similar trend was reported by Ahmad et al. (2018) who have reported the use of ANNs in $41 \%$ of studies reviewed by them.

\section{Performance Analysis of various Techniques} Qualitative assessment of basic modelling techniques

To assess the suitability of various prediction techniques for application in early-design-decision support tools it is important to have an understanding of their capabilities, limitations and modelling approaches. Table 3 provides a broad comparative, based on methodology and modelling approach, building information \& data

\begin{tabular}{|c|c|c|c|c|c|}
\hline 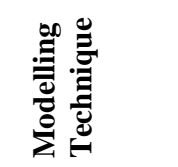 & 糈 & 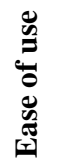 & 我泀 & 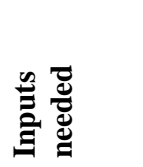 & : \\
\hline $\begin{array}{l}\text { Elaborate/ } \\
\text { Detailed } \\
\text { Engineering }\end{array}$ & $\begin{array}{l}\text { Fairly } \\
\text { high }\end{array}$ & No & Low & Detailed & $\begin{array}{l}\text { Fairly } \\
\text { high }\end{array}$ \\
\hline $\begin{array}{l}\text { Simplified } \\
\text { Engineering }\end{array}$ & High & Yes & High & Simplified & High \\
\hline Statistical & Fair & Yes & $\begin{array}{l}\text { Fairly } \\
\text { high }\end{array}$ & $\begin{array}{l}\text { Historical } \\
\text { data }\end{array}$ & Fair \\
\hline ANNs & High & No & High & $\begin{array}{l}\text { Historical } \\
\text { data }\end{array}$ & High \\
\hline$\overline{\text { SVM }}$ & $\begin{array}{l}\text { Fairly } \\
\text { high }\end{array}$ & No & Low & $\begin{array}{l}\text { Historical } \\
\text { data }\end{array}$ & $\begin{array}{l}\text { Fairly } \\
\text { high }\end{array}$ \\
\hline
\end{tabular}
required and the accuracy of results.

Table 3: Comparative performance of prediction techniques; Source (Zhao and Magoulès 2012)

Whereas, model complexity for detailed engineering and simplified engineering methods is high, they also show a corresponding high accuracy of the result. Detailed/ simplified information of building geometry, weather etc. is required for Elaborate/Detailed Engineering as well as Simplified Engineering models. However, the high complexity of modelling along with the requirement of detailed information/inputs about the building is a deterrent for their use in early-designdecision support tools.

In contrast, the modelling complexity and the result accuracy of statistical techniques is 'fair'. But, the performance and capability in terms of prediction accuracy is limited because of an assumption of linearity which may not exist in reality. Also, the performance 
falls when the range of input parameters is significantly changed from the range of data set used for training the regression model. Running speed is high for simplified engineering methods and ANNs. Model complexity (not for end user) and prediction accuracy of ANNs and SVMs are again 'high' / 'fairly high' respectively.

However, from the perspective of suitability for an early design decision support tool, data driven techniques present the opportunity of reducing modelling complexity for end user since only parametric inputs for predictor variables is required instead of a complex model of the building geometry. Moreover, much of the information regarding building geometry is not available at all in EDS.

\section{Quantitative assessment of modelling techniques}

For existing buildings, ANN based models have been shown to outperform BPS software. Neto and Fiorelli (2008) compared the performance of an ANN model with a BPS model (using EnergyPlus simulation) for predicting daily total electricity consumption $(\mathrm{kWh})$ of Administrative Building of the University of Sao Paulo. EnergyPlus consumption forecasts presented prediction errors of $12 \%-16 \%$ in comparison to about $10 \%$ in case of ANN. Massana et al. (2015) compared three models (MLR, ANN and SVM) for making short term load forecast for a Non- residential building. MLR presented a Mean Absolute Percentage Error (MAPE) of $4.68 \%$ compared to ANN $(0.45 \%)$ and SVM $(0.06 \%)$. Chou and Bui (2014) compared prediction models with various techniques including ANN, SVM, CART, CHAID, GLR and ensemble model. 768 experimental datasets from the literature were used with 8 input parameters and 2 output parameters (cooling load and heating load). Ensemble model (SVM+ANN) showed substantially improved performance.

\section{Limitations of Data-driven Techniques/ Models}

1. They may not give accurate predictions if input values lie outside of their training data range.

2. AI based models like ANNs are 'black-box' models, they are not interpretable and do not provide a detailed understanding of underlying relationships between predictor and response variables.

\section{Conclusions and observations}

Data-driven techniques/ models are better suited for early design stage decision support tools as only parametric values of predictor variables are required as input.

Performance of different techniques may vary from model to model depending on factors like input parameters used, type/quality of data available for training, suitability of a technique to the specific type of model etc. However, for EDS decision support, a normal distribution of prediction errors is important.

Input parameters play a crucial role in model accuracy. Sensitivity analysis of input variables is desirable for parameter selection. Parameters like meteorological factors and occupant behavior are difficult to model accurately and bring an element of uncertainty in energy prediction. Uncertainty analysis and calibration of prediction models is suggested by Fumo (2014).

$\mathrm{AI}$ and Machine learning techniques have been indicated as promising in literature because of 'superior capability to handle the complex input and output relationship' (Raza and Khosravi, 2015). ANN based models show better performance than statistical and time series methods for forecasting problem and result accuracy can be enhanced using integrated/ensemble approach.

No technique is universally better than others, performance-wise. However, authors Z. Wang, Wang, and Srinivasan (2018) and Z. Wang and Srinivasan (2017) have presented a strong case for ensemble methods coupling more than one techniques to improve performance.

To sum up, Building Energy Prediction and Optimization requires careful selection of input parameters and modelling techniques, coupled with a suitable model-calibration strategy to ensure good performance and accurate results.

Early-design-stage decisions require comparing multiple design options to evaluate implications of design decisions in terms of Capital and Operational/Life Cycle costs of buildings.

Data-driven models can make the process simpler as they need elementary parametric information (available at EDS). These techniques can be used at the back-end of a tool, while the decision makers/end users are only required to think about the input parameters in a way that is common knowledge for them (example Built-up area, glass \& other materials, window-to-wall ratio etc).

\section{References}

Agami Reddy, T. 2006. "Literature Review on Calibration of Building Energy Simulation Programs: Uses, Problems, Procedure, Uncertainty, and Tools." In ASHRAE Transactions, 112 PART 1, 226-40.

Ahmad, Tanveer, Huanxin Chen, Yabin Guo, and Jiangyu Wang. 2018. "A Comprehensive Overview on the Data Driven and Large Scale Based Approaches for Forecasting of Building Energy Demand: A Review." Energy and Buildings 165: 301-20.

Amasyali, Kadir, and Nora M. El-Gohary. 2018. "A Review of Data-Driven Building Energy Consumption Prediction Studies." Renewable and Sustainable Energy Reviews 81 (March 2017): 11921205.

Attia, Shady, Elisabeth Gratia, André De Herde, and Jan L.M. Hensen. 2012. "Simulation-Based Decision Support Tool for Early Stages of Zero-Energy Building Design.” Energy and Buildings 49: 2-15.

Bambardekar, Suhas, and Ute Poerschke. 2009. "The Architect As Performer of Energy Simulation in the Early Design Stage." In Proceedings of Building Simulation 2009, Eleventh Internationa IBPSA Conference, 1306-13. Glasgow, Scotland. 
Bazjanac, Vladimir, Tobias Maile, Cody Rose, James T O Donnell, Elmer Morrissey, and Benjamin R Welle. 2011. "An Assessment of the Use of Building Energy Performance Simulation in Early Design." In Proceedings of Building Simulation 2011: 12th Conference of International Building Performance Simulation Association, Sydeny, 1579-85.

Bureau of Energy Efficiency. 2017. Energy Conservation Building Code 2017. India: Bureau of Energy Efficiency, Ministry of Power, Government of India.

Chou, Jui Sheng, and Dac Khuong Bui. 2014. "Modeling Heating and Cooling Loads by Artificial Intelligence for Energy-Efficient Building Design." Energy and Buildings 82: 437-46.

Cortina, Jose M. 1993. "Interaction, Nonlinearity, and Multicollinearity: Implications for Multiple Regression.” Journal of Management 19 (4): 915-22.

Foucquier, Aurélie, Sylvain Robert, Frédéric Suard, Louis Stéphan, and Arnaud Jay. 2013. "State of the Art in Building Modelling and Energy Performances Prediction: A Review." Renewable and Sustainable Energy Reviews 23: 272-88.

Fumo, Nelson. 2014. "A Review on the Basics of Building Energy Estimation." Renewable and Sustainable Energy Reviews 31: 53-60.

Haykin, S. 2008. Neural Networks and Learning Machines. Pearson Prentice Hall New Jersey USA 936 PLinks.

Hester, Joshua, Jeremy Gregory, and Randolph Kirchain. 2017. "Sequential Early-Design Guidance for Residential Single-Family Buildings Using a Probabilistic Metamodel of Energy Consumption.” Energy and Buildings 134: 202-11.

Hygh, Janelle S., Joseph F. DeCarolis, David B. Hill, and S. Ranji Ranjithan. 2012. "Multivariate Regression as an Energy Assessment Tool in Early Building Design." Building and Environment 57: 165-75.

Indian Green Building Council. 2012. Annexure-II; Prescriptive Criteria for Building Envelope Measures. IGBC Green Homes Rating System.

International Energy Agency. 2017. "Key World Energy Statistics."

Jaccard, James, and Robert Turrisi. 2003. Interaction Effects in Multiple Linear Regression. 2nd edn. Sage Universtiy Papers Series on Qunatitative Applications in the Social Sciences,07-072, Thousand Oaks, CA:Sage.

Koenigsberger, O. H., T. G. Ingersoll, Alan Mayhew, and S. V. Szokolay. 2010. Manual of Tropical Housing and Building: Climatic Design.

Laustsen, Jens. 2008. "Energy Efficiency Requirements in Building Codes. Energy Efficiency Policies for
New Buildings.” International Energy Agency (IEA) Information Paper.

Massana, Joaquim, Carles Pous, Llorenç Burgas, Joaquim Melendez, and Joan Colomer. 2015. "ShortTerm Load Forecasting in a Non-Residential Building Contrasting Models and Attributes.” Energy and Buildings 92: 322-30.

Neto, Alberto Hernandez, and Flávio Augusto Sanzovo Fiorelli. 2008. "Comparison between Detailed Model Simulation and Artificial Neural Network for Forecasting Building Energy Consumption.” Energy and Buildings 40 (12): 2169-76.

Østergård, Torben, Rasmus L. Jensen, and Steffen E. Maagaard. 2016. "Building Simulations Supporting Decision Making in Early Design - A Review." Renewable and Sustainable Energy Reviews 61: 187-201.

Østergård, Torben, Rasmus L. Jensen, and Steffen E. Maagaard. 2017. "Early Building Design: Informed Decision-Making by Exploring Multidimensional Design Space Using Sensitivity Analysis.” Energy and Buildings 142: 8-22.

Raza, Muhammad Qamar, and Abbas Khosravi. 2015. "A Review on Artificial Intelligence Based Load Demand Forecasting Techniques for Smart Grid and Buildings." Renewable and Sustainable Energy Reviews 50: 1352-72.

Soebarto, Veronica, Christina J Hopfe, Dru Crawley, and Rajan Rawal. 2015. "Capturing the Views of Architects about Building Performance Simulation to Be Used during Design Processes.” In Proceedings of 14th International Conference of Building Performance Simulation Association, Hyderabad, India. Hyderabad, India: IBPSA.

Wang, Haidong, and Zhiqiang (John) Zhai. 2016. "Advances in Building Simulation and Computational Techniques: A Review between 1987 and 2014." Energy and Buildings 128: 319-35.

Wang, Zeyu, and Ravi S. Srinivasan. 2017. “A Review of Artificial Intelligence Based Building Energy Use Prediction: Contrasting the Capabilities of Single and Ensemble Prediction Models." Renewable and Sustainable Energy Reviews 75 (September 2015): 796-808.

Wang, Zeyu, Yueren Wang, and Ravi S. Srinivasan. 2018. "A Novel Ensemble Learning Approach to Support Building Energy Use Prediction.” Energy and Buildings 159: 109-22.

Zhao, Hai Xiang, and Frédéric Magoulès. 2012. “A Review on the Prediction of Building Energy Consumption." Renewable and Sustainable Energy Reviews 16 (6): 3586-92. 